\title{
USE OF ACTIVE AND PASSIVE VERB FORMS IN PAPERS FROM THE FIELD OF CHEMICAL ENGINEERING
}

\begin{abstract}
The paper deals with use of active and passive verb forms in journal articles from the field of chemical engineering with focus on heavy metal ions removal from water. Three hypotheses about use of passive and active voice were formed and tested on six scientific journal papers in the above mentioned field - three experimental and three theoretical. The data were gathered using a comparative analysis of active and passive verb forms with a share of statistical analyses. Hypothesis 1 "In scientific papers from the field of chemical engineering passive voice is more frequent than the active voice." is not valid as the active verb forms outnumber the passive verb forms though not significantly. Hypothesis 2 "Passive voice is much more common in Methods and Discussion sections than in the Introduction or Results sections." can only be applied to experimental papers and is valid as the passive verb forms outnumber the active ones in the particular sections. Hypothesis 3 "There is no difference in usage of passive and active voice in theoretical and experimental scientific papers." is not valid as in experimental papers the passive verb forms outnumber the active ones, on the other hand, in theoretical papers this statement does not apply.
\end{abstract}

Keywords: Active voice, passive voice, chemical engineering, comparative analysis.

\section{Introduction}

One of very specific use of spoken and/or written language is its use in science. Worldwide, though many of them written in a local language of the country where the research is conducted, the greatest number of scientific publications is written in the English language. English is also the required international language of communications, information technology, business, aviation, entertainment, radio and diplomacy.

It is generally accepted that the language used in science is different from "general English". The main difference is considered to be especially the more frequent use of passive. A passive construction is regarded as impersonal and distant. It also supports the idea of research without emotions and a strong emphasis on factuality, fidelity, intelligibility, and clarity.

The purpose of the paper is to outline the use of English language in scientific articles in the field of chemical engineering with focus on heavy metal ions removal from water with a special interest in active and passive voice. The correct application of active and passive in journal articles is one of the basic tools for mastering the theory and practice of paper-writing. For a nonnative speaker of English mastering the fragile balance between the two antinomies is vital but not that simple.

\subsection{Scientific writings}

Goldbort [1] defines scientific or technical English as a number of things - a tool for communication, a culture of writing, and a way of writing that is straight-lined and austere with strategies and uses of language of a very specific order - allowing the scientific community to conduct all the professional affairs. To be able to master the specificity of the language scientists depend on narrowly restricted uses of words. The advantage of this specific way of communicating has been explained by the linguist Leonard Bloomfield [2] as "The use of language in science is specialized and peculiar. In a brief speech the scientist manages to say things which in ordinary language would require a vast amount of talk. His hearers respond with great accuracy and uniformity. The range and exactitude of scientific prediction exceed any cleverness of everyday life: the scientist's use of language is strangely effective and powerful. Along with systematic observation, it is this peculiar use of language which distinguishes science from non-scientific behaviour."

Further on, "technical," "technological," "scholarly," "academic," "research" or "scholastic" English/writing/paper is referred to as "scientific" English/writing/paper due to the necessity of unifying these terms for the purpose of the paper

\footnotetext{
* ${ }^{1}$ Tomas Bakalar, ${ }^{2}$ Magdalena Razusova, ${ }^{3}$ Henrieta Pavolova, ${ }^{4}$ Barbara Hlavnova

${ }^{1}$ Institute of Mountainous Science and Environmental Protection, Faculty of Mining, Ecology, Process Control and Geotechnologies, Technical University of Kosice, Slovakia

${ }^{2}$ Institute of British and American Studies, Faculty of Arts, University of Presov, Slovakia

${ }^{3}$ Institute of Business and Management, Faculty of Mining, Ecology, Process Control and Geotechnologies, Technical University of Kosice, Slovakia ${ }^{4}$ Institute of Geotourism, Faculty of Mining, Ecology, Process Control and Geotechnologies, Technical University of Kosice, Slovakia

E-mail: tomas.bakalar@tuke.sk
} 
as different authors refer to the same subject under different denominations.

Scientists, according to Glass [3], in their profession publish at least five distinct pledges. In order to achieve the purposes of the writings effectively Goldbort [1] identifies six basic kinds of purposes that researchers have when they write particular documents for particular readers: recording and archiving, professional exposition or dissemination of research results, teaching, job duties, seeking financial resources, and informing citizens. In scientific activity itself, the most immediately important uses of language occur in making a reliable and permanent record or archive of research methods, outcomes, and conclusions.

Hill et al. [4] define scientific paper as a published or unpublished paper. The central purpose is to present the results of an experiment or ex post study. Published scientific papers appear in scholarly journals in most applied, hard, and social sciences. Unpublished scientific papers include theses, dissertations, term papers written for classes, and papers delivered at professional conferences and symposia. Although the style and content of scientific papers vary greatly from field to field and audience to audience, scientific papers share a common rhetorical organisation

\subsection{Organisation of scientific writings}

In scientific papers, Hill et al. [4] identify three organisational structures: the beginning - called the introduction; the middle called the procedure including methods and methodology and results; and the ending - called the discussion. What separates the introduction, procedure, and discussion sections from each other are their functions within the scientific paper. The introduction provides a transition from the larger academic field to the particular experiment. The procedure section describes the particular experiment. The discussion, like the introduction, is a transition too, but its purpose is to guide the reader from the particular experiment back to the larger academic area. The overall organisation is from general to particular and back to general.

\subsection{Passive voice in scientific writings}

In general verbs denote all kinds of actions, processes or events; sometimes they can even express states [5]. Being part of the denotation, a process or a state, therefore, belongs to the semantics of a verb. In particular, stativity is a purely semantic notion.

Passive verbs are much more common in science and engineering textbooks than in humanities textbooks [6]. It has long been accepted that one of the most salient grammatical features of scientific English, as compared to "general English", is its relatively frequent use of the passive form of the verb [7]. Frequency counts of verb tense and aspect performed on corpora of data which combine texts from a variety of scientific and technical fields do seem to show that, overall, the passive voice is used extensively in scientific English.

Passive voice allows for the subject of a sentence to be deleted, and thereby deemphasized in terms of its semantic role [8]. Passive voice can involve the deletion of the original subject. The effect is usually regarded as impersonal prose, precisely because the agent is deleted. Chafe and Danielwicz [9] characterise sentences in passive voice as detached and impersonal, as compared to those in active voice, since passives background or omit mentioning the agent of the action. Such agentless actions serve to distance the writer or speaker from the text, permitting opinions to be presented and generalized without overt attribution. In some instances the subject is deleted because the object is the topic of discussion, so that the "recorded results" are the focus, not the "recorder" [10]. Agentless passive can also be employed to front thematic information or remove the agent from the prominent sentence position [11]. In fact, scientific' passive" [12] is closely associated with the conventionalized rhetorical constructs specific to Anglo-American academic writing.

Voice choices can indeed contribute to revealing a stance [13 and 14]. The passive voice is useful in this regard as by allowing for the aforementioned shift of focus, there is the potential for the author's personal emphasis to be seen. Therefore, it is this potential to emphasize one sentential argument over another that is the suggested means by which passive voice can contribute to a writer's stance.

The dense use of passive verbs in academic prose is interesting because it is used merely to sound objective and to distance the practice of science from human agents [6]. While it is conventional to use passives to report research findings in many fields, there are also functional factors that affect the choice of passive.

In many cases where passives are used, the subject of an active voice verb would just be a vague group of researchers [6].

Fahy [15] opposes frequent use of passive in scientific papers, especially in the field of nursing. "In scientific writing 'active' rather than 'passive voice' is generally preferred." Using the active voice the subject names the agent of the action. Many scientific sentences have more than one possible subject and more than one verb. The writer must be clear about which noun in any given sentence is the "real" subject of the sentence. The subject should appear early in the sentence. Putting the subject early in each sentence assists to write sentences simple, active, and brief.

While the active voice is preferred in most writing the passive voice is often indispensable when the object or receiver of the action of the verb is more important than the doer, as often happens in the Materials and Methods section of scientific articles [16]. In this case, the active subject is usually self-evident, 
or unimportant, but sometimes, this construction is overused and sounds maladroit and complicated.

Using the passive voice appropriately, however, appears to be complex because of its contextual, lexical, and semantic constraints [17].

\section{Objectives}

We undertook to examine in more detail the frequency of occurrence of the active and passive forms of the verbs, i.e. active and passive voice in six journal papers in the field of chemical engineering. Considering that the degree of uniformity of textual structures in scientific texts depends on the discipline to which those texts belong [18 and 19], we did not select our sources from a wide range of disciplines, but gathered the papers belonging to one discipline.

We investigated, in particular, the rhetorical function of the passive in these texts. The six papers chosen for investigation were published in Applied Geochemistry, Separation Science and Technology, Water Research, and Hydrometallurgy, and focus on heavy metal ions removal from water.

Three are of theoretical character (review papers) whilst three papers are experimental scientific papers.

Based on the review in chapter 1.3 we made the following hypotheses:

Hypothesis 1: In scientific papers from the field of chemical engineering passive voice is more frequent than active voice.

Hypothesis 2: Passive voice is much more common in methods and discussion sections than in the introduction or results section.

Hypothesis 3: There is no difference in usage of passive and active voice in theoretical and experimental scientific papers.

For hypothesis 1 we decided in spite of the implication given by Fahy [15] and Espinoza [16].

\section{Methodology}

We did an initial survey of journal papers in the field of chemical engineering with focus on heavy metal ions removal from water and selected the six above mentioned articles based on publisher, country of origin of the authors, and type of article. The former two mentioned are not of the interest of the paper; nevertheless, the fact that the author(s) is/are non-native speaker(s) may have certain influence on the choice of verb forms.

\subsection{Comparative analysis of active and passive verb forms}

In our count and analysis, we counted finite verb phrases. We did not include bare past participles. Nor did we count verbs in footnotes, titles, data on receipt and acceptance, nomenclature, key words, tables and figures captions, acknowledgements or references. We did not count the symbol " $=$ " as a verb, though at times it functioned as a verb. We did not count "is" as a verb in nomenclature included in the text.

We counted as passive all verbs which appeared in the "subject + be + past participle" form. In case of coordinating clauses whose verb phrases are conjoined and one of the verb phrases is active and the other one is passive, we counted one active verb and one passive verb. In case of coordinating clauses whose verb phrases are conjoined and both the verb phrases are either active or passive we counted only one verb, either active or passive. In case of coordinating clauses whose two or more sentences are conjoined we counted both the verbs irrespective of the voice.

In addition to counting all active verb forms, we counted a subcategory of first person plural active verb forms, which represent a clear contrast to the use of passive.

We formulated hypotheses as to the apparent rhetorical function of choices between active verbs and passive verbs. The first author of the paper, who is an expert in the field of chemical engineering with a special interest in heavy metal ions removal from water using a hybrid method of adsorption and microfiltration and has a 10-year experience in the research, provided the interpretation of the text and outlined the overall rhetorical structure of these papers.

\subsection{Statistical analysis}

We can summarise and describe data using different numerical indicators. Central tendency, variability, and proportional representation (the sample mean, variance, and percentiles, respectively) are the most common ones. It is important that any characteristic of interest in a sample can be represented by a number [20 and 21].

\section{Results}

In comparing the frequency of the passive and active voices occurring in two astrophysics journal papers, the passive seems to be used when the authors simply follow established or standard procedures; when the authors refer to their own proposed future work; and describe the works of others (unless that work is mentioned in contrast to the author's) [7]. 


\subsection{Experimental papers}

The studied experimental papers completely match the scheme of three organisational structures [4] also described in chapter 1.2.

\subsubsection{General overview}

The papers comprise an Introduction chapter that gives the overall theoretical background for the study based on the previously published works from the same field.

The middle section of the papers is represented by a description of each experiment conducted and discussed in the paper. The titles of the chapters, though, are different. These differences may not only be caused by the choice of the author(s) but also be determined by the publishers [22 and 23].

The Discussion sections of the papers give the results of the experiments drawn in the middle section which are discussed in a wider meaning of the knowledge in the scientific field.

Only in one paper out of the three studied, active verb forms outnumber passive verb forms, as shown in Table 1. If we look only at the incidence of active "we" verb forms as opposed to passive, we find that the authors do not favour this subcategory of verb forms. Only one "we" verb form out of 243 active verbs and of 517 verbs (active + passive) is found in the three studied experimental papers.

The overall tendency for all the three papers is to prefer the passive to the active. In scientific experimental journal papers in the field of chemical engineering, the passive verb form occurs more frequently than the active, and the first person plural we verb form is rare.

\subsubsection{Comparative analysis}

In the paper by Bunker et al. [24] passive verb forms outnumber active verb forms only in the Abstract section. In the
Introduction and Methodology sections the number of active and passive verb forms is equal and in the Results, Discussion and Conclusion sections the number of passive verb forms is below the number of active verb forms. The mean percentage of the passive verb forms occurrence is $41.69 \%$ and the standard deviation is $17.03 \%$.

In the paper by Mizera et al. [25] passive verb forms outnumber active verb forms in the Experimental and Conclusion sections, yet there is no active verb form in the Experimental section.

In the remaining Abstract, Introduction and Results and Discussion sections the number of passive verb forms is below the number of active verb forms, though in the Abstract and Results and Discussion sections the difference is only 1 and 2 verbs, respectively. The mean percentage of the passive verb forms occurrence is 59.17 and the standard deviation is 25.17.

In the paper by Tran and Roddic [26] passive verb forms outnumber active verb forms in the Abstract, Introduction, Materials and Methods and Results and Discussion section. In the remaining Conclusion section the number of passive verb forms is below the number of active verb forms, though the difference is only 1 verb. The mean percentage of the passive verb forms occurrence is 65.40 and the standard deviation is 13.29 .

Further we compared the frequency of occurrence of the active and passive forms of the verbs in particular sections crucial for the analysis, i.e. Introduction, Methods and Results and Discussion sections of all the three experimental papers. According to these results the ratio of the active to passive verb forms is greater in Methods sections than in Introduction and Results and Discussion sections thus passive voice is preferred in the Methods sections.

\subsection{Theoretical papers}

As Tarone et al. [7] underline an important fact sometimes forgotten in the field of scientific English - "not all scientific journal papers consist of reports of experimental studies," - this

Frequency of Active and Passive Verbs in Experimental Papers

Table 1

\begin{tabular}{|l|c|c|c|c|c|c|c|c|c|}
\hline Author(s) & \multicolumn{3}{|c|}{ Bunker et al. [24] } & \multicolumn{3}{c|}{ Mizera et al. [25] } & \multicolumn{3}{c|}{ Tran and Roddic [26] } \\
\hline & Count & $\%$ & $\%$ & Count & $\%$ & $\%$ & Count & $\%$ & $\%$ \\
\hline * & 1 & 2 & 3 & 1 & 2 & 3 & 1 & 2 & 3 \\
\hline Total number of words & 3164 & 100.00 & & 3237 & 100.00 & & 3939 & 100.00 & \\
\hline Total number of verbs & 198 & 6.26 & 100.00 & 145 & 4.48 & 100.00 & 174 & 3.66 & 100.00 \\
\hline Active verbs & $\mathbf{1 1 6}$ & 3.67 & 58.59 & $\mathbf{6 2}$ & 1.92 & 42.76 & $\mathbf{6 5}$ & 1.35 & 36.81 \\
\hline Passive verbs & $\mathbf{8 2}$ & 2.59 & 41.41 & $\mathbf{8 3}$ & 2.56 & 57.24 & $\mathbf{1 0 9}$ & 2.31 & 63.19 \\
\hline Active "we" verbs & 0 & 0.00 & 0.00 & 1 & 0.03 & 0.69 & 0 & 0.00 & 0.00 \\
\hline
\end{tabular}

* 1 - total absolute number in the whole article; 2 - percentage from the total number of words in the whole article; 3 - percentage from the total number of verbs in the whole article. 
Frequency of Active and Passive Verbs in Theoretical Papers

Table 2

\begin{tabular}{|l|c|c|c|c|c|c|c|c|c|}
\hline Author(s) & \multicolumn{3}{|c|}{ Dambies [28] } & \multicolumn{3}{c|}{ Davis et al. [29] } & \multicolumn{3}{c|}{ Volesky [27] } \\
\hline & Count & $\%$ & $\%$ & Count & $\%$ & $\%$ & Count & $\%$ & $\%$ \\
\hline * & 1 & 2 & 3 & 1 & 2 & 3 & 1 & 2 & 3 \\
\hline Total number of words & 6211 & 100.00 & & 9176 & 100.00 & & 5165 & 100.00 & \\
\hline Total number of verbs & 435 & 7.00 & 100.00 & 605 & 6.59 & 100.00 & 334 & 6.47 & 100.00 \\
\hline Active verbs & $\mathbf{2 8 2}$ & 4.54 & 64.83 & $\mathbf{3 7 6}$ & 4.10 & 62.15 & $\mathbf{2 4 3}$ & 4.70 & 72.75 \\
\hline Passive verbs & $\mathbf{1 5 3}$ & 2.46 & 35.17 & $\mathbf{2 2 9}$ & 2.50 & 37.85 & $\mathbf{9 1}$ & 1.76 & 27.25 \\
\hline Active "we" verbs & 2 & 0.03 & 0.46 & 9 & 0.10 & 1.49 & 0 & 0.00 & 0.00 \\
\hline
\end{tabular}

* 1 - total absolute number in the whole article; 2 - percentage from the total number of words in the whole article; 3 - percentage from the total number of verbs in the whole article.

consideration also applies to papers in the field of chemical engineering.

\subsubsection{General overview}

In astrophysics, journal papers do not consist of experimental studies for a very simple reason: the subject matter does not lend itself to experimentation. One cannot experiment on a star or a galaxy in the way in which one can experiment on a chemical compound or a bean plant. The field of astrophysics therefore publishes papers describing logical arguments rather than experiments. Journal papers in astrophysics consist of logical arguments which cite observations and draw conclusions based on logic, citations of established procedures, and proposals for new choices and procedures, all involving the use of mathematical equations.

The situation in the field of the papers from the field of chemical engineering is not the same. Though scientists in this field can perform and successfully do experiments mostly on a chemical background, theoretical papers are often brought to summarize the growing number of experimental results in the same field of study, compare results of different authors on the same topic, or get together same experiments performed by different methods.

In all the three theoretical papers, active verb forms greatly outnumber passive verb forms, as shown in Table 2. If we look only at the incidence of active "we" verb forms as opposed to passive, we find that the authors do not favour this subcategory of verb forms that is in accordance to the finding concerning experimental papers. Though eleven "we" verb forms out of 901 active verbs and of 1374 verbs (active + passive) are found in the three studied theoretical papers, namely as follows, it represents only 1.22 per cent of all the used active verbs. Based on the list above and Table 2, there is no "we" verb form in the paper by Volesky [27].

While there does seem to be some individual variation in the frequency of active verb forms and passive verb forms, the overall tendency for all the three papers is to prefer the active to the passive. Thus, if these three papers are representatives of the writing style in this field and kind of paper, it seems that in scientific theoretical journal papers in the field of chemical engineering, the passive verb form occurs less frequently than the active, and that the first person plural we verb form occurs much less often as other active or the passive verb forms.

\subsubsection{Comparative analysis}

As it is not possible to apply the organisational structure of papers presented in chapter 1.2, we counted the verbs in particular chapters that we could unanimously identify and divided them into sections: Abstract, Introduction, "Main text," and Conclusion.

Further on we compared the frequency of active verb forms and passive verb forms in particular chapters as defined above.

In the paper by Dambies [28] active verb forms outnumber passive verb forms in the Introduction, Main text and Conclusion sections. The mean percentage of the passive verb forms occurrence is 57.54 and the standard deviation is 34.03 .

In the paper by Davis et al. [29] active verb forms outnumber passive verb forms in all the sections. The mean percentage of the passive verb forms occurrence is 69.18 and the standard deviation is 8.76 .

In the paper by Volesky [27] active verb forms outnumber passive verb forms also in all the sections. The mean percentage of the passive verb forms occurrence is 75.73 and the standard deviation is 2.91 .

\section{Discussion}

The overall rhetorical structure of a professional journal paper in the field of chemical engineering takes the shape of a logical argument in which the author attempts to solve a problem by choosing that combination, from among various 
accepted procedures and equations, which will best solve the problem.

Hypothesis 1 In scientific papers from the field of chemical engineering passive voice is more frequent than active voice. Based on the analysis introduced in chapter 4 this hypothesis is not valid for the studied papers and thus for the papers published in the field of chemical engineering with focus on heavy metal ions removal from water as a whole. The overall mean percentage of the active verb forms occurrence is $56.03 \%$ and of the passive is $43.97 \%$ although the difference is almost negligible. However, this hypothesis is only valid for all the 6 studied papers and cannot be evaluated in the same way if we take the criterion of the kind of papers, which will be further discussed in the assessment of Hypothesis 3.

Hypothesis 2 Passive voice is much more common in methods and discussion sections than in the introduction or results section. This hypothesis is not applicable for theoretical papers considering it is not possible to differentiate the Methods, Discussion and Results sections since they do not exist. The structure of theoretical papers is different from the structure of a scientific paper described in chapter 1.2 which is also discussed in chapter 4.2.2. Experimental papers, as introduced in chapter 4.1.2, comply with the structure of scientific papers described in chapter 1.2, but only in the paper published by Bunker et al. [24] all the four above mentioned sections, i.e. introduction, methods, discussion, and results, can be differentiated. In the remaining two papers published by Mizera et al. [25] and Tran and Roddic [26] the Results sections are immersed into the Discussion sections so we excluded the coupled Results and Discussion sections from the statistical analysis for these cases. Considering the above mentioned, this hypothesis is valid for the studied experimental papers i.e. for the experimental papers published in the field of chemical engineering with focus on heavy metal ions removal from water. The ratio of the active verb forms to the passive ones in the Methods and Discussion sections of all the three experimental papers is approximately 12:10 whilst this ratio in the Introduction and Results sections of all the three experimental papers is $10: 11$.

Hypothesis 3 There is no difference in usage of passive and active voice in theoretical and experimental scientific papers. Based on the presented results and conclusions from hypotheses 1 and 2 this hypothesis is not valid for the studied papers i.e. for the papers published in the field of chemical engineering with focus on heavy metal ions removal from water. In case of experimental papers the passive verb forms outnumber the active ones. The overall mean percentage of the passive verb forms occurrence is, though not significantly, higher than that of active ones, i.e. $55.42 \%$ and $44.58 \%$ respectively. In case of theoretical papers the active verb forms greatly outnumber the passive ones. The ratio of the active verb forms to the passive ones is approximately $2: 1$, i.e. $67.49 \%$ compared to $32.51 \%$, respectively.

\section{Conclusion}

The generalisations made in the paper concerning the occurrence of active and passive verb forms were based on six scientific articles appearing in prestigious journals on heavy metal ions removal from water, which is a subdiscipline of chemical engineering. Passive voice has an important role in writing papers. Placing the object of the sentence in the subject position is the basic function of passive voice; from a rhetorical point of view this gives one sentential element prominence over another. Textual cohesion, not personal emphasis, is very often an important factor to take into consideration, as well as placement within the topicality hierarchy.

Three hypotheses were formulated on usage of active and passive voice in scientific papers. For the papers published in the field of chemical engineering it is possible to generalise that passive voice is not more frequent than the active one. But this statement is only valid if both theoretical and experimental papers are considered. If the criterion of the type of papers is considered, there is a significant difference. In experimental papers passive voice is preferred unlike in theoretical papers, for which active voice is dominant. Concerning the structure of the papers theoretical papers are organised in a different way as experimental ones. As theoretical papers are not reports on experiments but summaries of other experimental papers from the same field, they do not consist of the Methods, Discussion and Results sections. For the experimental papers that do follow the three organisational structures it can be concluded that passive voice is more common in Methods and Discussion sections than in the Introduction and/or Results sections.

\section{References}

[1] GOLDBORT, R.: Writing for Science, Yale University Press, New Haven \& London, 2006.

[2] BLOOMFIELD, R.: Linguistic Aspects of Science, Phil. Sci., vol. 2, No. 4, pp. 499-517, 1935.

[3] GLASS, B.: The Ethical Basis of Science, Science, vol. 150, No. 3701, pp. 1254-1261, 1965.

[4] HILL S. S., SOPPELSA, B. F., WEST, G. K.: Teaching ESL Students to Read and Write Experimental-Research Papers, TESOL QUART., vol. 16, No. 3, 1982.

[5] ROTHMAYR, A.: The Structure of Stative Verbs, John Benjamins Publishing Company, Amsterdam/Philadelphia, 2009. 
[6] BIBER, D., CONRAD, S.: Register, Genre and Style, Cambridge University Press, 2009.

[7] TARONE, E., DWYER, S., GILlETTE, S., ICKE, V.: On the Use of the Passive and Active Voice in Astrophysics Journal Papers: With Extensions to other Languages and other Fields, Engl. Spec. Purposes, vol. 17, No. 1, pp. 113-132, 1998.

[8] BARATTA, A. M.: Revealing stance through passive voice, J. Pragmatics, vol. 41, No. 7, pp. 1406-1421, 2009.

[9] CHAFE, W. L., DANIELEWICZ, J.: Properties of Written and Spoken Language, Horowitz, R., Samuels, S. J. (Eds.), Comprehending Oral and Written Language, Academic Press, San Diego, CA, 1987.

[10] REILLY, J., ZAMORA, A., Mc GIVERN, R. F.: Acquiring Perspective in English: The Development of Stance, J. Pragmatics, vol. 37, pp.185-208, 2005.

[11] JACOBS, R. A.: English Syntax: A Grammar for English Language Professionals, Oxford University Press: Oxford, 1995.

[12] ATKINSON, D.: Discourse Analysis and Written Discourse Conventions, Annual Rev. Applied Linguistics, vol. 11, pp. 57-76, 1991.

[13] THOMPSON, G., Ye, Y.: Evaluation in the Reporting Verbs Used in Academic Papers, Applied Linguistics, vol. 12, No. 4, pp. 365-382, 1991.

[14] HYLAND, K.: Persuasion and Context: The Pragmatics of Academic Metadiscourse, J. Pragmatics, vol. 30, No. 4, pp. 437-455, 1998.

[15] FAHY, K.: Writing for Publication: The basics, Women and Birth, vol. 21, No.2, pp. 86-91, 2008.

[16] ESPINOZA, A. M.: Contrastive Analysis of the Spanish and English Passive Voice in Scientific Prose, English Spec. Purposes, vol. 16, No. 3, pp. 229-243, 1997.

[17] HINKEL, E.: Indirectness in L1 and L2 Academic Writing, J. Pragmatics, vol. 27, No. 3, pp. 361-386, 1997.

[18] GNUTZMANN, C., OLDENBURG, H.: Contrastive Text Linguistics in LSP-research: Theoretical Considerations and Some Preliminary Findings, Schroder, H. (Ed.), Subject-oriented Texts, Walter de Gruyter, Berlin, 1991.

[19] MARTIN, P. M.: A Genre Analysis of English and Spanish Research Paper Abstracts in Experimental Social Sciences, English Spec. Purposes, vol. 22, pp. 25-43, 2003.

[20] DELORME, A.: Statistical Methods, available on-line [25 Feb 2011]: http://sccn.ucsd.edu/ arno/mypapers/statistics.pdf

[21] FLOREKOVA, L., BENKOVA, M.: Statistical Methods (in Slovak). Technicka univerzita v Kosiciach, 1999.

[22] Author Information Pack for Applied Geochemistry, available on-line [21 Feb 2011]: http://www.elsevier.com/wps/find/ journaldescription.cws_home/768/authorinstructions

[23] Author Information Pack for Water Research, available on-line [21 Feb 2011]: http://www.elsevier.com/wps/find/journaldescription. cws_home/309/authorinstructions

[24] BUNKER, D. J., SMITH, J. T., LIVENS, F. R., HILTON, J.: Kinetics of Metal Ion Sorption on Lake Sediments - Approaches to the Analysis of Experimental Data, Applied Geochem., vol. 16, No. 6, pp. 651-658, 2001.

[25] MIZERA, J., MIZEROVA, G., MACHOVIC, V., BORECKA, L.: Sorption of Cesium, Cobalt and Europium on Low-rank Coal and Chitosan, Water Res., vol. 41, No. 3, pp. 620-626, 2007.

[26] TRAN, H. H., RODDICK, F. A.: Comparison of Chromatography and Desiccant Silica Gels for the Adsorption of Metal Ions - II. Fixed-bed study, Water Res., vol. 33, No. 13, pp. 3001-3011, 1999.

[27] VOLESKY, B.: Detoxification of Metal-bearing Effluents: Biosorption for the Next Century, Hydrometallurgy, vol. 59, No. 2-3, pp. 203-216, 2001.

[28] DAMBIES, L.: Existing and Prospective Sorption Technologies for the Removal of Arsenic in Water. Separ. Sci. Technol., vol. 39, No. 3, pp. 603-627, 2004.

[29] DAVIS, T. A., VOLESKY, B., MUCCI, A.: A Review of the Biochemistry of Heavy Metal Biosorption by Brown Algae, Water Res., vol. 37, No. 18, pp. 4311-4330, 2003. 